\title{
The Tourism Destination Image Perception of Guizhou Ethnic Village Based on Online Reviews
}

\author{
Jianchun Yang, Jialian Wang \\ Guiyang 550025, China \\ 772957289@qq.com \\ 杨建春, 王佳联 \\ 贵州财经大学工商学院 \\ 贵阳 550025，中国 \\ 772957289@qq.com
}

School of Business, Guizhou University of Finance and Economics

\section{基于网络评论的贵州民族村寨旅游地形象感知研究}

\begin{abstract}
Taking Guizhou ethnic villages as research subject, this paper uses 6416 online reviews of Ctrip tourists as data sources and explores tourists' perception on tourism destination image of Guizhou ethnic village through content analysis. The results indicate that the tourism destination image perception of Guizhou ethnic village is composed of tourism environment, tourism resources, tourism facilities and tourism services. The ethnic villages have the advantages of beautiful scenery, unique culture, simple folk customs and so on, but some villages also have problems such as inconvenient transportation, serious commercialization and poor sanitation. On this basis, relevant countermeasures and suggestions are put forward to promote the sustainable development of Guizhou ethnic village tourism.
\end{abstract}

Keywords—ethnic villages, tourism destination image, image perception, online reviews

摘要一选取贵州民族村寨为研究对象，以携程游客的 6416 条网络评论作为数据来源, 运用内容分析法探讨游客对贵州民 族村寨旅游地形象的感知。结果表明, 贵州民族村寨旅游地形 象感知由旅游环境、旅游资源、旅游设施、旅游服务构成, 民 族村寨具有景色优美、文化独特、民风淳朴等优点, 但部分村 寨也存在交通不方便、商业化严重、卫生条件差等问题。在此 基础上进而提出相关对策与建议，以期促进贵州民族村寨旅游 的可持续发展。

关键词一民族村寨, 旅游地形象, 形象感知, 网络评论

\section{I. 引言}

旅游地形象作为影响旅游者决策和旅游地竞争力的 重要因素, 是评价旅游地发展状况的一项重要指标。良 好的旅游地形象有助于提高旅游地发展水平、改进管理 方式以及营造深度旅游体验等。尽管如此, 民族村寨在 旅游发展过程中出现了 “资源破坏、环境脆化、文化失 落、管理滞后” 等一系列问题, 民族村寨旅游地形象遭 到严重破坏。随着互联网的快速发展, 越来越多的游客 通过撰写网络评论来表达和反映其对旅游地形象的感 知, 网络评论已成为旅游地形象感知研究的重要数据来 通过文献梳理发现, 国内外学者从不同角度对旅游 地形象感知展开了一系列研究, 但在一定程度上忽视了
源。大数据时代背景下, 如何采集有效数据, 通过网络 评论探寻游客对民族村寨旅游地形象的感知, 塑造理想 的民族村寨旅游地形象, 成为学界和业界亟待解决的问 题。

\section{II. 相关研究回顾}

20 世纪 70 年代初, Hunt 首次提出旅游地形象感知的 概念, 1984 年之后成为国外旅游研究领域的热点并持续 至今。例如, Hunter (2016) 通过比较网上的照片与印 刷在手册及旅游指南上的传统投影影像来了解首尔的旅 游地形象感知 [1]。Stylos 等（2016）验证了旅游地整体 形象感知在预测游客重游目的地意愿方面的中介作用 [2]。Foroudi 等 (2018) 实证研究结果显示积极的旅游地 形象感知有助于提升游客的再访意愿与推荐意愿 [3]。伴 随着信息网络的高速发展，互联网传播下的旅游地形象 感知成为旅游研究的重点。Mak (2017) 对在线图片进 行分析发现台湾东部地区的旅游地形象感知主要由自然 环境、基础设施、特色活动、旅游景点构成[4]。Roig 等

（2018）分析 2015 年访问加泰罗尼亚游客的 8 万条英文 在线旅游评论发现旅游地形象感知在空间、认知和情感 方面存在差异 [5]。Liu 等 (2019) 运用情感分析模型比较 了中国游客和国际游客对澳大利亚旅游地形象的感知 [6]。

国内对旅游地形象感知的研究始于 20 世纪 90 年代后 期, 我国的旅游学者在借鉴国外研究成果的基础上, 进 一步拓展了该领域的研究范围。例如, 刘锐等 (2018) 实证研究发现城郊型乡村旅游地游客感知形象通过旅游 体验与满意度间接影响游客的行为意向 [7]。近年来，基 于网络信息的旅游地形象感知研究也是国内旅游研究的 热点。例如, 李萍等 (2017) 对百度旅游和携程网的 10 万余字的游客点评内容进行文本挖掘, 比较了不同旅游 社区的认知形象、情感形象以及总体形象感知 [8]。整体 而言, 学者们主要利用内容分析法聚焦于对景区[9]、古 城[10]、城市 [11]等的旅游地形象感知进行研究。

民族村寨旅游地形象感知的研究, 基于网络文本对其进 行探讨的学者更是鲜少。鉴于此, 本文采用内容分析法 
深入剖析游客对贵州民族村寨旅游地形象的感知, 为完 善与提升民族村寨旅游地形象以及民族村寨旅游管理实 践提供依据。

\section{III. 研究设计}

\section{A. 案例地概况}

贵州, 简称 “黔” 或 “贵”, 地处中国西南内陆地 区腹地。贵州民族村寨在喀斯特地形的 “封闭性保护” 下, 不仅保存有千姿百态的自然景观, 而且各民族丰富 多彩的传统文化没有被现代普世性文化和都市生活过多 的侵扰, 像这样全面、系统、集中、原生态地展示地方 民族传统文化, 保存有大量 “活的” 人类文化遗产的地 区，在我国乃至全球已经不多见。从二十世纪八十年代 开始, 贵州先后选择了安顺的布依石头寨、黔东南的上 郎德、南花、青曼、西江苗寨等八个民族村寨作为旅游 开发试验点。经过三十多年的积极探索, 目前民族村寨 旅游已成为贵州旅游业的重要支柱, 对其旅游地形象的 研究具有较强的典型代表性。

\section{B. 研究方法}

内容分析法是对研究对象的文本内容进行客观、系 统、量化分析的方法, 已被广泛应用于传播学、情报 学、社会学等领域。本文采用武汉大学沈阳教授研究团 队研发的 Rost Content Mining 软件作为内容分析工具。
在数据来源方面, 本文以携程旅行网作为游客评论的获 取渠道。携程网是当前我国最大的在线旅游经营商, 网 站开通时间最早, 知名度最高, 用户访问量最大, 旅游 评论十分丰富。本文利用八爪鱼采集器爬取了 2010 年 1 月至 2018 年 12 月时间段的携程游客评论, 剔除部分重 复内容后, 最终得到 6416 条有效网络评论。

$$
\text { IV. 结果分析 }
$$

\section{A. 高频词汇分析}

通过词频分析并删除无实际意义的词汇后, 本文从 游客评论中提取了前 60 个高频词汇, 具体结果见表 1 。 从词性来看, 高频词汇包括名词、形容词和动词。其 中, 名词词汇数量最多, 主要应用在景点、位置、景色 等方面, 形容词主要反映游客对村寨的印象及其环境感 受, 动词主要表现游客的具体活动。对高频词进行分析 可知, “苗寨”、“侗族” 等说明游客到贵州主要以游 览苗寨和侗寨为主; “值得”、“很好” 等体现了游客 对村寨较高的满意度; “客栈”、“民族”、“长桌 宴” 等说明村寨的住宿和饮食餐饮具有民族特色; “排 队”、“小时” 等说明村寨高峰期游客过多, 还需进一 步加强管理; “商业化”、“原生态” 说明不同村寨环 境氛围有明显差异; 另外, “门票”、“免费” 情况也 是游客极为关注的。

表 1 样本高频词汇表

\begin{tabular}{cc||cc||cc||cc||cc}
\hline 排名 & 词汇 & 排名 & 词汇 & 排名 & 词汇 & 排名 & 词汇 & 排名 & 词汇 \\
\hline 1 & 苗寨 & 13 & 侗族 & 25 & 梯田 & 37 & 特别 & 49 & 民族 \\
2 & 景区 & 14 & 晚上 & 26 & 体验 & 38 & 建议 & 50 & 风情 \\
3 & 寨子 & 15 & 景色 & 27 & 观景台 & 39 & 旅游 & 51 & 吊脚楼 \\
4 & 值得 & 16 & 比较 & 28 & 建筑 & 40 & 观光车 & 52 & 免费 \\
5 & 商业化 & 17 & 很好 & 29 & 当地 & 41 & 小时 & 53 & 漂亮 \\
6 & 西江 & 18 & 里面 & 30 & 客栈 & 42 & 开发 & 54 & 还不错 \\
7 & 苗族 & 19 & 方便 & 31 & 肇兴 & 43 & 交通 & 55 & 环境 \\
8 & 门票 & 20 & 游客 & 32 & 气息 & 44 & 排队 & 56 & 太多 \\
9 & 感觉 & 21 & 原生态 & 33 & 住宿 & 45 & 原始 & 57 & 长桌宴 \\
10 & 千户 & 22 & 鼓楼 & 34 & 生活 & 46 & 携程 & 58 & 价格 \\
11 & 特色 & 23 & 贵州 & 35 & 推荐 & 47 & 酒店 & 59 & 喜欢 \\
12 & 夜景 & 24 & 风景 & 36 & 文化 & 48 & 感受 & 60 & 演出 \\
\hline
\end{tabular}

\section{B. 情感分析}

由表 2 可知, 游客对村寨的整体认同度较高。

表 2 游客情感分析

\begin{tabular}{cccc}
\hline 情感类别 & 比例/\% & 强度 & 比例/\% \\
\hline 积极情绪 & 74.84 & 一般 & 35.70 \\
& & 中度 & 25.16 \\
& & 高度 & 13.98 \\
中性情绪 & 14.84 & $/$ & $/$ \\
消极情绪 & 10.32 & 一般 & 7.74 \\
& & 中度 & 1.94 \\
总计 & 100.00 & 高度 & 0.22 \\
\hline
\end{tabular}

表 2 中, 积极情绪所占比例最高, 为 $74.84 \%$, 主要 表现在景色优美、空气清新、气候宜人、村民热情好 客、民族风情浓郁等方面。但是也有 $10.32 \%$ 的游客持消 极态度，大多表现在交通不方便、商业化严重、卫生条 件差、餐饮性价比低等方面。此外, 有 $14.84 \%$ 的游客对 村寨印象持中性态度。总体而言, 游客对村寨的情感态 度趋于良好，对其宣传形象认同感强。

\section{C. 语义网络分析}

从图 1 可以看出, 村寨游客评论语义网络结构主要包 括四个层次: 一是最里层, 即核心层, 表明贵州村寨以 苗寨和侗寨为主, 游客评论焦点主要是村寨的门票价格 以及商业化程度; 二是里侧第二圈, 即次核心层, 展现 
大多数游客对村寨内主要吸引物的关注; 三是里侧第三 圈, 说明游客对村寨总体评价和认识, 对于村寨景色比 较满意; 四是最外圈, 即最外层, 主要诨涉游客对村寨 交通、住宿、管理、景点等的讨论。

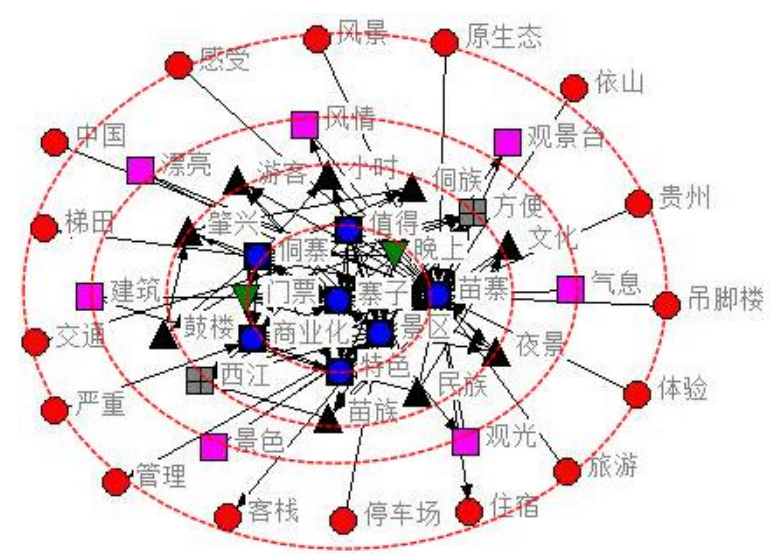

图 1 样本语义网络分析

\section{$D$. 旅游地形象感知分析}

贵州民族村寨旅游地形象感知构成主要表现在旅游环 境、旅游资源、旅游设施、旅游服务 4 个方面: (1)旅游 环境。游客对贵州民族村寨环境感知的评论较多。综合 而言, 大多数游客对村寨环境的情感态度是积极的, 总 体评价较高，使用了很多认可的词汇，如 “值得”、 “很好”、“推荐”、“漂亮”、“还不错”、“喜 欢” 等。但是也有一些负面态度, 比如, 部分游客觉得 商业化太严重导致大部分村寨千篇一律, 还有游客表示 村寨卫生也不太好。(2)旅游资源。“鼓楼”、“梯 田”、“吊脚楼”、“建筑”、“文化”、“演出”等 词汇表明村寨旅游资源以人文资源为主, 其对游客具有 较高的吸引力, 比如, 一些游客从侗寨的鼓楼、苗寨的 吊脚楼等旅游吸引物体验到了浓郁的民族风情。(3)旅游 设施。很多游客反映村寨的对外交通不太方便, “停车 场” 表明村寨仍然存在停车问题, 这会影响到游客的游 览体验。(4)旅游服务。“门票” 出现频率较高, 表明游 客较为关注村寨门票的价格。大部分游客认为门票较 贵, 性价比不高。但是 “方便”一词说明游客认为网上 购票、自动取票机上快速取票的方式非常方便。

\section{V. 结论与建议}

\section{A. 研究结论}

本文运用内容分析法研究游客对贵州民族村寨旅游地 形象的感知, 得出如下结论: (1)贵州民族村寨旅游地形 象的感知可以归纳为旅游环境、旅游资源、旅游设施、 旅游服务四大方面。(2)游客对村寨旅游满意度较好, 整 体评价较高, 凸显了村寨旅游良好的发展基础和强大的 竞争实力。(3)游客对村寨旅游地形象感知以积极情绪为 主, 但消极情感也占有一定比例, 不能忽视, 村寨应进 行有效的管理和改善。(4)游客对村寨清新的空气、宜人 的气候、优美的景色、独特的文化、淳朴的民风等方面 充满向往与认可。同时, 游客对村寨也存在一些负面的
评论, 如交通不方便、商业化严重、卫生条件差、餐饮 性价比低等。

\section{B. 对策建议}

基于研究结果, 本文对贵州民族村寨旅游地形象建设 提出以下建议: (1)不仅要拓宽国内旅游市场空间范围, 还要对国际化旅游市场进行定位, 吸引更多的海内外游 客前往村寨旅游。(2)开发丰富多样的旅游产品, 致力于 旅游商品的供给创新, 重视村寨自然资源的开发和推 广, 深度挖掘村寨特有的民族文化。(3)充分利用周围环 境, 因地制宜地建造停车场, 合理扩充停车位, 树立明 确的指示牌, 以满足游客需求。还要加强旅游交通建 设, 提高工作人员素质, 加强假期的人流疏导工作，提 升高峰期管理质量, 完善旅游自助服务。(4)实际考察游 客对门票价格的接受程度, 从而对门票价格进行调整, 并在宣传过程中增加相关门票信息, 以向游客提供更多 的便利。(5)管理部门应制定相应的餐饮质量服务标准, 以提高餐饮服务质量。适当增加村寨内餐饮, 合理调节 餐饮价格, 并对相关营业单位进行长期有效的监督。同 时，也需要对村寨环境卫生实施合理化管理。

\section{致谢}

本项目受教育部人文社会科学研究规划基金项目 “民族村寨旅游精准扶贫问题研究”（项目编号: 16YJAZH069) 和贵州财经大学 2018 年度在校学生科研 资助项目 “基于数据挖掘的贵州民族村寨旅游地形象塑 造路径研究”（项目编号：2018ZXSY65）联合资助。

\section{[1] 参考文献}

[2] W. C. Hunter, "The social construction of tourism online destination image: a comparative semiotic analysis of the visual representation of Seoul," Tourism Management, vol. 54, pp. 221-229, 2016.

[3] N. Stylos, C. A. Vassiliadis, V. Bellou, and A. Andronikidis, "Destination images, holistic images and personal normative beliefs: predictors of intention to revisit a destination," Tourism Management, vol. 53, pp. 40-60, 2016.

[4] P. Foroudi, T. N. Akarsu, E. Ageeva, M. M. Foroudi, C. Dennis, and T. C. Melewar, "Promising the dream: changing destination image of London through the effect of website place," Journal of Business Research, vol. 83, pp. 97-110, 2018.

[5] A. H. N. Mak, "Online destination image: comparing national tourism organisation's and tourists' perspectives," Tourism Management, vol. 60, pp. 280297, 2017.

[6] E. M. Roig, and B. F. Rosell, "Measuring the gap between projected and perceived destination images of Catalonia using compositional analysis," Tourism Management, vol. 68, pp. 236-249, 2018.

[7] Y. Liu, K. X. Huang, J. G. Bao, and K. Q. Chen, "Listen to the voices from home: an analysis of Chinese tourists' sentiments regarding Australian 
destinations," Tourism Management, vol. 71, pp. 337347, 2019.

[8] 刘锐, 卢松, 邓辉, “城郊型乡村旅游地游客感知形象 与行为意向关系研究—以合肥大圩镇为例, ”中国农 业资源与区划, vol. 39, issue 3, pp. 220-230, 2018.

[9] 李萍, 陈田, 王甫园, 王新歌, “基于文本挖掘的城市 旅游社区形象感知研究一以北京市为例, ”地理研究, vol. 36, issue 6, pp. 1106-1122, 2017.

[10] 皮瑞, 郑鹏, “网评少林: 少林寺旅游认知、情感、整 体形象研究,”干旱区资源与环境, vol. 31, issue 4, pp. 201-207, 2017.
[11] 蔡晓梅, 寸露, 朱䇈, “自我东方主义?丽江旅游形象 的想象与建构,”旅游学刊, vol. 33, issue 9, pp. 26-37, 2018.

[12] 仲宁, 吴小根, 汪侠, 穆小雨, “基于网络文本分析的 宜兴旅游地形象差异研究,”资源开发与市场, vol. 34, issue 8, pp. 1168-1172, 2018.

[13] 杨建春, 基于系统视角的民族村寨旅游发展研究. 北 京: 科学出版社, 2017. 